\title{
EL ETERNO REGRESO DEL MIGRANTE: LITERATURA Y VIDA EN LA TRILOGÍA AUTOBIOGRÁFICA DE ROBERTO BRODSKY ${ }^{1}$
}

\author{
Rodrigo Cánovas Emhart \\ Pontificia Universidad Católica de Chile \\ rcanovas@uc.cl
}

\section{RESUMEN / ABSTRACT}

En este trabajo presentaremos las obras Bosque quemado (2007), Veneno (2012) y Casa chilena (2015), del escritor Roberto Brodsky, formando parte de una trilogía autobiográfica en la cual se tematizan los efectos del derrumbe de las utopía sociales en el ámbito personal. Pondremos énfasis en: (1) la reflexión sobre los traumas que constituyen las historias personales y familiares derivados del exilio y el retorno durante los periodos de dictadura y postdictadura en Chile; (2) la construcción migrante del personaje, que extravía su sentido de pertenencia a un solo lugar, lo cual lo define desde el duelo y la melancolía, y (3) su configuración como escritor desde una autobiografía, entendida como una literatura que no aparta la vida, pero que se nutre de la ficción.

Palabras Clave: Roberto Brodsky, autobiografía, exilio y retorno, migrancia.

In this work we present the books Bosque quemado (2007), Veneno (2012) and Casa chilena (2015), written by Roberto Brodsky, which are shaped as a trilogy of autobiographical texts in which the author deals with the effects of the devastating decay of the social utopias in the individual world. We will emphasize on (1) the reflection about the traumas generated from exile and return during the periods of Chilean dictatorship and post-dictatorship that remodeled personal and family history; (2) the migrant construction of the character, that in a state of mourning and melancholy, looses his sense of belonging, with no place to settle;

1 Este trabajo forma parte del proyecto FONDECYT N¹130002 Relatos (auto) biograficos chilenos (1991-2011): nuevas y antiguas señas de identidad, del cual soy Investigador Responsable. 
and (3) the writer's identity accomplished by the act of writing an autobiography that intermingles life and fiction.

KEYWORDS: Roberto Brodsky, autobiography, Exile and Retournee, migrancy.

En sus inicios como novelista, Roberto Brodsky escribió novelas de género policial que constituían una indagación valórica sobre la dictadura y sus consecuencias para la convivencia ética de una sociedad. Ahora bien, con la aparición de Bosque quemado (2007) inicia un giro muy estricto hacia la escritura autobiográfica, que se prolonga con Veneno (2012) y Casa chilena (2014) y que amenaza con contaminar retroactivamente toda su obra narrativa ${ }^{2}$.

Este artículo es una primera reflexión sobre estos tres textos de carácter autobiográfico, entendiéndolos como una sola unidad, aunados por una misma voluntad de contar una vida desde alguien que dice yo, aun cuando éste no aparezca con su nombre propio (pero sí como el hijo de Moisés Brodsky, en Bosque quemado) o se ausente desde la tercera persona a través de un nombre extraño (el escritor Shapiro, antifaz del hijo de Moisés, en Veneno) o se desplace hacia la segunda persona, generándose desde un desdoblamiento, en Casa chilena.

Ha sido el propio autor quien ha señalado que intuyó este movimiento en espiral en medio de su travesía autobiográfica, habiendo comenzado a escribir, entonces, su última obra, con la plena convicción de estar hilando sobre el mismo tejido. En una entrevista reciente, realizada por M. Teresa Cárdenas para el diario El Mercurio, Brodsky lo explica así:

Las tres novelas conforman mi travesía por el desierto, por decirlo de un modo dramático, porque cada una cuenta un capítulo, un clima propio de ese viaje único que dibuja la alegoría de la casa. Esto lo he pensado ahora, pero funciona así, porque en Bosque quemado, por ejemplo, el narrador regresa con el padre después de diez años de exilio, y eventualmente recupera la casa, su territorio, aunque no tenga nada que celebrar. Veneno en cambio es el abandono: las cosas salen mal, el narrador tira la casa por la ventana, se va y vuelve,

2 Roberto Brodsky (Santiago de Chile, 1957) es un novelista (El peor de los héroes, Últimos días de la historia, El arte de callar, más la ya mencionada trilogía autobiográfica), que también ha escrito cuentos y realizado guiones para cine. Durante la década de los 80 , incursionó en el teatro como creador y actor. 
pero la promesa está perdida, el mundo está roto y hay que irse del discurso y del espacio literario que lo sustentaba, desarraigarse, pero esta vez por mano propia. Y ahora Casa chilena, que es el puro desasimiento, donde el narrador entrega la casa y se desprende de ese espacio alegórico de la memoria (E11).

Precisemos que estas obras pueden ser interpretadas como una unidad, justamente porque están compuestas como una tríada; lo cual no anula que cada una tenga su propio registro y pueda leerse de modo independiente. Obviamente, el lector ideal de cualquiera de estas obras es el que las ha leído todas; pero no necesariamente en orden, pues cada una constituye a las otras desde la alusión, como una segunda mirada o una intuición primera, que desplaza constantemente el relato, manteniéndolo en movimiento perpetuo.

En este artículo haremos énfasis en el singular modo de constitución autobiográfico de cada una de estas obras y despejaremos el orden estructural que articula la tríada, la cual sustenta la conformación de un sujeto en tránsito, testigo del derrumbe de las ilusiones modernas, ligadas en este caso al extravío de referencias simbólicas y afectivas en el plano familiar e ideológico.

Para la discusión sobre las Escrituras del Yo acudiremos a conceptos y definiciones pertinentes que nos ayuden a bosquejar una poética en ciernes sobre las relaciones entre literatura y vida propuesta en la obra de Roberto Brodsky ${ }^{3}$. En este sentido, las precisiones sobre la categoría de sujeto realizadas por Emile Benveniste serán muy valiosas para enunciar una identidad migrante desde el juego narrativo con la persona gramatical ${ }^{4}$.

3 De la vasta y arborescente bibliografía crítica sobre los relatos autobiográficos, tendremos en mente principalmente la compilación de Ángel Loureiro La autobiografía y sus problemas teóricos, de 1991 (que reúne los trabajos clásicos sobre el tema en la tradición francesa y anglosajona), el ensayo crítico de Sylvia Molloy Acto de presencia. La escritura autobiográfica en Hispanoamérica (1996) y el texto de Lorena Amaro Vida y escritura. Teoría y práctica de la autobiografía (2009). Para una discusión sobre la noción de autoficción, que rompe el pacto de veracidad que sustenta la autobiografía, tendremos presente el texto crítico de Manuel Alberca El pacto ambiguo. De la novela autobiográfica a la autoficción (2007) y la reciente compilación de Ana Casas El yo fabulado. Nuevas aproximaciones críticas a la autoficción (2014). Acudiremos a estas lecturas de modo puntual, para aclarar y contextualizar el pensamiento autobiográfico exhibido en la trilogía de Brodsky.

Para despejar las relaciones entre lenguaje y sociedad tendremos presente los planteamientos de Ėmile Benveniste en su Problemas de lingüística general; en especial la sección V del libro titulada "El Hombre en la Lengua". 
La reflexión sobre la crisis existencial del sujeto, ligada a una pérdida de referentes afectivos e ideológicos en el marco del exilio y del regreso al lugar natal, será abordada teniendo presente discursos críticos sobre memoria y migrancia ${ }^{5}$.

Nuestra exposición le dedicará una sección a cada obra donde haremos una presentación descriptiva del texto en cuestión, haciendo énfasis en sus relaciones con los demás textos, para luego, en un acápite final, proponer las redes de parentesco más visibles que componen y proyectan el conjunto.

\section{BOSQUE QUEMADO: EL HIJO QUE VA Y VIENE}

Esta obra autobiográfica gira en torno a la figura de Moisés Brodsky, padre del personaje, un médico comunista que debe partir en 1973 hacia el exilio, instalándose primero en Buenos Aires para pronto huir de allí por la Guerra Sucia y vivir precariamente en Caracas y calcinarse en un poblado oriental de ese país, denominado Lechería, para volver finalmente a Santiago de Chile, luego de diez años de exilio, convertido en cadáver viviente. Morirá arrasado por el Alzheimer en plena transición a la democracia durante los años 90, despojado de todos sus quereres y con la memoria en blanco ${ }^{6}$.

5 Nuestra lectura se sitúa dentro del gran marco general de la reflexión sobre la condición postmoderna, según la clásica definición de J.-F. Lyotard: "Simplificando al máximo, se tiene por 'postmoderna' la incredulidad con respecto a los metarrelatos . . . Al desuso del dispositivo metanarrativo de legitimación corresponde especialmente la crisis de la filosofía metafísica y la de la institución universitaria que dependía de ella. La función narrativa pierde sus actores, el gran héroe, los grandes peligros y el gran propósito" (10). Para los discursos sobre memoria y migrancia, tendremos en cuenta las consideraciones de Andreas Huyssen sobre el Holocausto, la amplia revisión histórica que realiza Abril Trigo sobre la migración como proceso traumático en la historia moderna y contemporánea y, en al ámbito chileno, los breves ensayos sobre identidad y exilio incluidos en la compilación de Sonia Montecino Revisitando Chile.

6 Bosque quemado puede incluirse en la amplia serie de los relatos sobre el retorno (del exilio). Para situar esta serie consideramos de gran utilidad la lectura de breves ensayos (que se podrían denominar cápsulas crítico-subjetivas) incluidos en la compilación de Sonia Montecino Revisitando Chile; específicamente, los de Luis Mizón, Ana Pizarro y Loreto Rebolledo. Así por ejemplo, en el texto de Ana Pizarro, leemos: "El retornado vive entonces en un entre-lugar de la vida y la cultura, en un espacio de negociación, entre el pasado que lo destruyó y lo rehizo, y este presente que también está en su memoria histórica pero es diferente a las imágenes que ella conservaba. Dependerá de las circunstancias y de sus recursos íntimos 
Un Moisés que ha extraviado su camino; no es ésta, sin embargo, la historia del padre (nunca se nos habla desde su conciencia), sino la del hijo, aquel huérfano que lo sigue como guardián y emisario por esas cartografías migrantes, sirviendo de enlace afectivo y culposo con la familia y también con el proyecto utópico marxista, y convirtiéndose en el nuevo judío errante latinoamericano ${ }^{7}$.

La novela se abre con unos golpes en la puerta, como si el destino llamara al personaje a emprender nuevos derroteros. En el Nuevo Chile de los años 90, Moisés toca la puerta del departamento de su hijo menor, el que lo ha seguido a todas sus peregrinaciones, para que lo acoja: "Mi padre dice soy yo, tu padre, ábreme" (15). Irónico nudo de la orfandad: un hijo en busca de amparo debe acoger al supuesto guía de la tribu. Son los nidos vacíos de una familia en tránsito, cuyo supuesto drama se inicia años antes del Golpe Militar, cuando la mujer de Moisés se instala a vivir con otro hombre, de condición social menor y mucho más joven que ella.

Exilio marxista, errancia judía, sujetos suspendidos en el aire o girando en redondo. El hijo -que jamás pronuncia su nombre, que anda a tientas por el mundo-, le sigue los pasos al padre, para que no se extravíe, reditando antiguas redes familiares -la parentela judía bonaerense- y a la vez él mismo agregando puntos de fuga a esta cartografía latinoamericana: se instala por un tiempo en Barcelona, pero de allí sale expulsado, volviendo entonces a Santiago, donde recién se ha reinstalado su padre. Desde la escritura en el

el lograr equilibrar esta tercera etapa de su viaje, y de este equilibrio dependerá, a su vez, el resto de su vida" (90). Moisés muere aquejado del Alzheimer; mientras que su hijo seguirá entrando y saliendo del país, armando su lugar natal al modo de un puzzle al que le faltan piezas, en una escritura ensimismada.

Consideramos que este hijo se concibe como un migrante, un sujeto en tránsito, que no logra asimilarse a ningún lugar. Atraemos aquí una imagen identitaria del migrante propuesta por Abril Trigo, que nos parece pertinente para toda la tríada y ejemplar para Bosque quemado: "El migrante habita el tiempo-espacio como un hábitat móvil, porque la migrancia, en su ir y venir, siempre en tránsito, termina por disolver la identificación inalienable y certera con un espacio-tiempo circular, y por ello, la promesa del regreso a casa se vuelve imposible... Esto implica que en el proceso el migrante termina enajenándose de ambos mundos, experiencia que se caracteriza por un vital sentimiento de homelessness (Heidegger), de orfandad (Said), de forasterismo (Arguedas), de extrañamiento social, cultural y existencial por el cual no se siente en casa en parte alguna, y que lo diferencia del cosmopolita" (277). Esta migrancia tiene un rasgo distintivo: la errancia judía (a la cual nos referimos centralmente en este acápite del artículo dedicado a Bosque quemado). 
recuerdo, escuchamos: "mi padre era mi país, mi patria portátil. Yo sería del lugar donde estuviese él" (70).

En el amplio juego intertextual de esta primera obra con las siguientes, hemos elegido comentar tres aspectos: la itinerancia, una familia y un país, y la raigambre judía.

Si en Bosque quemado el personaje gira en redondo alrededor de su padre, quien ha perdido su centro; en Veneno y en Casa chilena sus personajes homólogos transitan entre Washington D.C. y Santiago de Chile, figurándose desde la vertical Norte/Sur, amparándose en dos casas, es decir, en dos países. No se piense, sin embargo, que esos personajes estén aquí más amparados, pues en realidad es como si vivieran en dos medias casas, que no pueden juntarse. Como ya veremos, en Veneno el escritor Shapiro se siente desterrado de su querido Chile, refugiándose con su familia en el País del Norte. Y a su vez, el personaje de Casa chilena hace una breve visita a su tierra natal chilena, para vender la casa de los padres, situada en el barrio de su infancia; lo cual no lo liberará de seguir retornando. Es importante indicar que, en el caso de Veneno, el juego entre dos espacios se exhibe claramente tanto en el ámbito de lo nacional (vivir separado de la patria) como familiar; en efecto, en el refugio extranjero la casa se parte en dos: está la propia (usada como taller de escritura) y la otra, donde ha ido a refugiarse su grupo familiar, para una mejor convivencia.

Volviendo a Bosque quemado, esta obra autobiográfica gira en torno al "desgüese familiar" (129) visto desde la perspectiva del hijo; desgüese que tiende a repetirse, cuando el hijo llega a ser padre en los siguientes textos. Ahora bien, esta primera obra revela una fortaleza, que se proyectará en el tiempo: la pertenencia del personaje a la familia judía, que se manifiesta en el amparo que le otorga en su huida la rama familiar bonaerense -el nostálgico recuerdo de "los almuerzos familiares de los días domingo" (168);- lo cual lo hace regresar muchos años después donde sus primos porteños para la celebración del primer bar mitzva de la familia paterna en suelo latinoamericano.

Considero que este hijo logra concebir una identidad que se mantiene en sordina en las siguientes obras desde su adherencia al tronco judaico, que le permite resituarse en el mundo. ¿Cómo rescatar la figura debilitada del padre, cómo nombrarse a sí mismo? Desde el presente de la escritura, interpreta la vida de Moisés desde la tradición del pueblo elegido, a saber: la elección de la medicina como una disciplina sagrada, el abrazo del comunismo como un mandato mesiánico, su exilio como un círculo más de la espiral diaspórica, que en el ámbito familiar se inició con el viaje de la matriarca 
Ana Kotlowicz hace cien años desde la localidad de Dnepropetrovsk a una esquina perdida del mundo ${ }^{8}$.

Ahora bien, la medicina y el comunismo constituyen también cartas de asimilación en los discursos de la nación moderna; pero que en el caso de Moisés no logran atajar el descalabro del Alzheimer, enfermedad que es explicada por el doctor con una metáfora escolar: "Imaginen que su cerebro fue víctima de un incendio que arrasó con recuerdos, referencias, memoria, todo ... Un bosque quemado donde todavía quedan algunos árboles y ramas humeantes" (124). Y es aquí donde se desata otro ánimo judío: el miedo ancestral al daño?.

Los lazos judíos como único suelo; la vivencia desplazada de las persecuciones durante la era nazi y la Shoah (cuerpos quemados, alma cenicientas), y el miedo del ser humano a transformarse en una memoria extinta. Estos son los derroteros de las letras migrantes chilenas en su rizo inicial, que luego se van desplazando hacia otros parajes, a saber, el artista escribiendo una obra que no tiene cabida (Veneno), el personaje viendo desaparecer una casa fantasma (Casa chilena); parajes que se superponen en el continuo desplazamiento del sujeto por la contrahecha realidad -un país, la literatura, el hogar-, que se le escapa.

Volviendo a la impronta judaica, ésta contamina Veneno desde su raíz, por el nombre del personaje: Shapiro. A su vez, este viajero que elige EE.UU. como un punto de residencia -al igual que el de Casa chilena-nos remite a una posible Tierra Prometida, una casa que no tiene lugar en Chile.

$8 \quad$ En su artículo "En el nombre de Moisés (Bosque quemado de Roberto Brodsky)", Jorge Scherman propone una lúcida lectura sobre esta relación padre-hijo, teniendo presente la figura del Judío Errante. Plantea también, dentro del círculo de la literatura judaica, que esta obra sería una inversión de la Carta al padre de Kafka (mencionada y comentada en Boque quemada, a propósito de una carta de Moisés), una vindicación: "un gesto literario de redención post mortem, en el nombre de Moisés" (200).

9 La proposición de Andreas Huyssen de que el discurso del Holocausto funciona como una metáfora de otras historias traumáticas recientes se cumple ejemplarmente en Bosque quemado: "El Holocausto devenido tropos universal es el requisito previo para descentrarlo y utilizarlo como un poderoso prisma a través del cual podemos percibir otros genocidios" (17). Ahora bien, Huyssen señala también el imperativo de exhibir de modo pormenorizado esas historias locales, para que así el Holocausto no se transforme en un metarrelato encubridor o simple dispositivo de traducción global. En la trilogía autobiográfica de Brodsky la interacción de lo local y lo global permite un diálogo fecundo entre el discurso del Holocausto y los relatos de dictadura y postdictadura en Chile. 
Siguiendo con los paralelismos entre las dos primeras obras, en ambas se experimenta el arte visual como un modelo de interpretación y resolución de los grandes enigmas de la vida: la creación, la muerte, el acogimiento. Así, el personaje de Bosque quemado comprende de golpe que su padre tiene el mal de Alzheimer ante la visión de la serie fotográfica del japonés Tatsumi Orimoto, que muestra a su madre con la mente en blanco, rodeada de marraquetas de pan de diversa forma y tamaño, objetos nutricios tras los cuales también se parapeta el artista nipón: "Me estremecí y el pavor me invadió. A mi mente acudieron relojes, paquetes, bolsas plásticas, ruidos de llaves, cucharas y tenedores abandonados en el baño [de mi departamento, donde vive actualmente mi padre] junto a un arsenal de movimientos en falso que percutían sobre los muros como el cadáver del arte moderno azotado en el aire retenido del museo" (87).

Este estremecimiento ante una exposición en el Museo de Bellas Artes, en Santiago de Chile, nos remite a uno sufrido por el escritor Shapiro -ahora estamos en Veneno- ante la visión de las siete telas del inmigrante letón Mark Rothko (primitivamente nominado Markus Rothkowitz) en una visita al National Gallery en Washington D.C. Estas telas, recubiertas solo con el color negro en distintas tonalidades y matices, le señalan al personaje escritor un posible modelo para capturar la experiencia sin que ésta sea anulada por el acto de la representación. Por cierto, es una alusión al proyecto de escribir un libro que transite subrepticiamente entre la literatura y la vida. Que aquí el personaje Shapiro interprete esta serie de telas como una performance adelantada de la muerte del mismo Rothko (no olvidemos que este artista de origen judío se suicida), acaso vincule el arte como oráculo de la vida, pudiendo ser mortaja o alivio para los cuerpos sufrientes.

Es como si el arte iluminara aspectos que no quisiéramos ver; y en este caso particular, como si a la vez ayudara a sanar o acompañar en el sufrimiento al ser humano. En el caso de Bosque quemado, Orimoto fotografiándose con su madre, el hijo de Moisés escribiendo su vida acoplado a su padre; ambos intentando colmar una carencia, de nutrirlos, de nutrirse, no importando si el gesto sea impúdico, regresivo o simple egocentrismo. Es el Yo del artista, apoyado en el débil hilo del tramado familiar.

Finalmente, queremos mencionar el desajuste del personaje de Bosque quemado con la comunidad chilena, no solo en el periodo dictatorial, sino muy especialmente en la postdictadura. Singularmente, nos referimos a los años 90, en que Chile es declarado por el hijo del cardiólogo -el comunista que regresa a su patria y es débilmente reivindicado por la institución nacional 
a la cual le había dedicado su vida-, "la casa de Alzheimer" (140). Un país sin sustento, un padre humillado, una comunidad sin memoria.

El hijo se sitúa como el testigo que resiente la adaptación, que aparece irónicamente retratada en la pareja de jóvenes estudiantes de medicina Manuela y René, sus vecinos en un condominio santiaguino: "la generación de los felices [...] la generación salvada" (88). Pareja que se revela como un doble invertido de la inestable pareja que forma el personaje en la actualidad. Paradójicamente, este hijo infeliz mantiene por un tiempo una relación sexual, clandestina por cierto, con su vecina Manuela. ¿Un modo de incorporarse a este nuevo orden social (incorporación fallida, pues hay desamor)? ¿Una pequeña venganza reivindicativa de este migrante? ¿Una inoculación del padre (del discurso del padre) en las nuevas generaciones? Indiquemos desde ya que el procedimiento del doble como un modo paradójico de constitución del Yo está muy presente en la trilogía; así por ejemplo, en Casa chilena, hay una pareja que no quiere abandonar la casa que arrienda, actuando así la imposibilidad del mismo dueño de la casa, que está de paso por Chile precisamente para poder deshacerse de ella.

La experiencia existencial de desajuste radical con Chile se continúa naturalmente en Veneno, referido al rompimiento de los lazos de solidaridad en el ámbito cultual y más aún, en Casa chilena, donde el país es una casa comercial. Indiquemos, sin embargo, que en este último caso, nuestro personaje ya no lucha por cambiar el presente, sino más bien por contaminarlo de pasado en su espíritu.

\section{VENENO: EL REGRESO CLANDESTINO DEL ARTISTA}

Alberto Shapiro viene invitado por el gobierno chileno para participar en un seminario en el marco de la celebración del Bicentenario (nos ubicamos, entonces, en el año 2010), titulado Foreign Brain Storm; puesto que vienen especialistas de diversas áreas del conocimiento que viven en el extranjero que discutirán la agenda del futuro -ironía aparte. Shapiro, quien cerrará en encuentro con su conferencia "Los chilenos de la diáspora", regresa luego de una ausencia de dos años, desde Washington, donde está instalado con su familia; sin embargo, es alguien que ha estado entrando y saliendo de la casa chilena desde su adolescencia, a raíz del Golpe Militar chileno de 1973. Se diría entonces que es un chileno que ha vivido puertas afuera. 
El presente del relato abarca los días del Seminario, situado en el marco de una semana de noviembre en la capital chilena; pero las asociaciones libres $\mathrm{y}$ disquisiciones del personaje sobre su vida se mueven en el amplio espectro del fluir de su vida familiar y de escritor, yendo y viniendo por lugares y tiempos diversos que convergen en el espacio de un discurso, cuya tarea es colmar una orfandad o constatarla de modo contradictorio. Anotemos que junto con citarse otros tiempos biográficos, se citan también libros anteriores de este personaje -centralmente, una nominada ficción documental acerca de su padre, que corresponde a Bosque quemado (publicada en 2007). Y siguiendo un movimiento en espiral, también es una cita prospectiva del libro que sucederá a Veneno, que nuevamente trae al personaje a Chile, esta vez con un nuevo ajuste de cuentas sobre el pasado: Casa chilena, de 2015.

Si estamos en la esfera de los escenarios del yo y de modo específico, del relato autobiográfico, es ineludible presentar al personaje por su nombre propio. En Veneno, se nos presenta a Alberto Shapiro, de profesión escritor, nombre que no corresponde al de Roberto Brodsky. En la novela anterior, Bosque quemado, alguien (innominado) nos contaba desde la primera persona las peripecias suyas con su padre Moisés Brodsky, por lo cual podríamos conjeturar con alto grado de certidumbre el nombre de este hijo que acompaña a su padre comunista de modo intermitente durante su exilio latinoamericano hasta su vuelta a Chile. Estaríamos en presencia, entonces, desde la clásica clasificación de Philippe Lejeune, de una novela autobiográfica, pues los datos otorgados en la trama nos obligan a pensar en el parecido de la vida del personaje con la vida del autor ${ }^{10}$.

10 Recordemos la definición de Philippe Lejeune para la novela autobiográfica: "llamaré así a todos los textos de ficción en los cuales el lector puede tener razones para sospechar, a partir de parecidos que cree percibir, que se da una identidad entre el autor y el personaje, mientras que el autor ha preferido negar esa identidad o, al menos, no afirmarla" (52). Por el contrario, define la autobiografía como un relato en el cual coinciden plenamente la identidad del autor, del narrador y el personaje; planteándose como un texto veraz. En el caso de la novela autobiográfica, Lejeune precisa: “A diferencia de la autobiografía, implica gradaciones: El 'parecido' supuesto por el lector puede ir desde un vago 'aire de familia' entre el personaje y el autor, hasta la casi transparencia que lleva a concluir que se trata el autor "clavado"" (52). Desde la perspectiva de Lejeune, en Bosque quemado, al no poner el autor a su personaje un nombre propio, se deja en suspenso el principio de identidad que funda a la autobiografía. Para una acabada presentación conceptual del relato autobiográfico, consúltese el texto de Lorena Amaro Vida y Escritura. Teoría y práctica de la autobiografía. La tríada de Brodsky 
En el caso de Shapiro, el parecido existe, pero es más lejano o capcioso. Si el lector ha leído la primera obra, la continuidad es evidente, pues se alude a la novela del padre, dando indicios claros de la continuidad de este parecido. Si no la ha leído, y a pesar de la aparente dificultad de que este segundo texto esté narrado en tercera persona, desde las primeras páginas hay un juego con el nombre del personaje. Así, en el primer capítulo, se menciona casualmente que para este Seminario se le ha otorgado en su carpeta de identificación una "chapa de identificación" (19), como si Alberto Shapiro fuera un nombre clandestino usado por el personaje para volver de incógnito en el plano de un relato sobre su vida. Más adelante y muy especialmente con la aparición del escritor Roberto Bolaño como personaje, se sigue autogenerando el nombre del autor desde contextos históricos y biográficos (la amistad de ambos escritores, fácilmente verificable vía internet); lo cual permite conjeturar que el llamarse Alberto es como llamarse Roberto (comparten dos sílabas); que de paso genera una inquietud: Bolaño y Brodsky comparten el mismo nombre... Siendo Bolaño una especie de hermano mayor en el área simbólica de la vida literaria del personaje, es posible también que haya sido él quien le otorgue ese nombre como chapa o seudónimo ficticio, como se nos sugiere en el vivificante encuentro de los dos escritores en Blanes, España: "mientras Bolaño contaba de un tal Schapiro, con ceache y judío como él, pero checo este otro y autor de un cuento llamado 'La cruz' que Alberto debía sin duda leer, mira que escribir un cuento con ese ese título siendo judío ... ."(143-144) $)^{11}$.

Ahora bien, si en Bosque quemado habla alguien en primera persona, pero no se nombra (como si tuviera primero que hablar en el nombre del padre, para luego pronunciar sus primeras letras con propiedad) y si en Veneno se usa la tercera persona para referirse a un tal Shapiro (pudiéndose cambiar todo el relato a la primera persona, sin modificarse el sentido, como

puede discutirse también con propiedad desde la noción de autoficción, como veremos más adelante -cf. infra, nota 18 .

11 En realidad, el juego de nombres propios y pronombres en Veneno se torna aún más intrincado cuando, de modo excepcional, un capítulo entero de la novela es narrado desde alguien que dice de modo explícito yo, indicándonos en esta instancia que es autor de una novela cuyo personaje ficticio se llama Bruno Marconi -protagonista de la primera novela de Roberto Brodsky, El peor de los héroes-y procediendo a continuación a esbozar una nueva historia para el personaje Marconi. En este capítulo se estaría actuando la creación autobiográfica desde un juego de cajas chinas: dentro de un personaje (de la ficción), el personaje de la vida (el escritor) y nuevamente, dentro del escritor, su doble en la ficción. 
si estuviera hablando el personaje, cual muñeco manejando al ventrílocuo); en la última obra, Casa chilena, el personaje se desplaza hacia la segunda persona, generándose un desdoblamiento, a modo de una actuación de una vida que resulta ser, a final de cuentas, la propia, cuyo pasado está entreverado en los anteriores relatos.

Los primeros pasos de este escritor lo llevan a la acomodada casa de su antiguo amigo Frank, conocido editor a quien Shapiro le había confiado un manuscrito -la novela donde habla sobre su padre-, que finalmente se publica en el extranjero. La escena tiene un marcado rasgo visual, situándonos como espectadores de un film, donde dos personajes aparecen ensimismados y sellados sobre sí mismos, en un juego narcisista de rivalidades. Son las hermandades, resueltas en relaciones simbióticas de carácter negativo: en la vida literaria, el desencuentro entre el editor y el escritor, relación sadomasoquista que aquí está presentada desde la perspectiva del sufriente; y en la escena edípica, por cierto, el lance entre hermanos, "enemigos íntimos" (69). Como ya se ha adelantado, uno de los modos de constitución de los personajes en esta trilogía es el doble, es decir, los personajes se generan como proyecciones de un yo, en sus diversas modalidades; en el caso de Frank, la necesidad íntima de un enemigo o el engañoso distanciamiento de una fuerza autodestructiva. Como bien reflexiona en tono melancólico el personaje central (el yo que irradia): "Los males que le atribuía a Frank se inspiraban en los suyos" (36).

Veneno pone en escena a los actores e instituciones que modelan el circuito del libro, infartándolo de mediocridad y narcisismo, con el daño para el escritor, incluida su contaminación. La situación es compleja: no solo se trata de un mercado medido en la relación costo-beneficio y de una relación desigual de poder entre los actores participantes; sino también, a nivel íntimo y subjetivo, de una sorda rivalidad fraterna (nada menos que las sombras de Abel y Caín) que conllevan el enviscamiento del yo. Son los complejos caminos de la creación, el enfrentamiento con un origen esquivo (el país, lo perdido, lo buscado) y su resolución ambivalente. ¿Quién legitima a cada uno de estos actores? ¿Cuán víctima es Shapiro de sí mismo? ¿Qué reconocimiento piden los poderosos actores secundarios -lectores de manuscritos, editores, críticos mediáticos- de este drama? Lo cierto es que todos están encadenados y en esta ocasión, en este libro, cada uno cuida su espacio particular, sin que medie una fuerza mayor. Acaso, a nivel simbólico, falta algo o alguien que se erija como una ley (una creencia, 
una voz patriarcal); pero ese espacio está vacío, al menos en el Chile vivido en este libro y en los demás de la trilogía ${ }^{12}$.

Es en esta atmósfera de rivalidades y servidumbres que aparece en la pantalla de la conciencia del personaje la figura del escritor Roberto Bolaño, a quien suponemos le debe su nombre o chapa (Shapiro). Junto al nudo de las hermandades (el personaje y Frank); aparece el núcleo de las filiaciones, es decir, la posibilidad de emparentarse a un modelo de vida (artístico) y de conformar una constelación que permita una instalación en el universo simbólico de los signos y de la vida. Bolaño será aquí la figura emblemática. Más adelante se agregarán, desde su estadía en Washington D.C. las figuras del crítico cultural Ángel Rama y del escritor Juan Carlos Onetti.

Uno de los centros vitales del texto es la vuelta a casa. ¿Cómo reaparecer en escena de un modo rotundo? Es en esta coyuntura que Bolaño aparece como un modelo digno de estudio del periplo del héroe que intenta una vuelta definitiva a casa (puede marcharse nuevamente, pero su nombre iluminará un presente absoluto). En alrededor de 42 páginas se nos otorga un retrato de este Roberto exitoso, siguiendo sus pasos desde su regreso a Chile con su novela premiada Los detectives salvajes y sus polémicas para llamar la atención en los círculos literarios. En un gesto autobiográfico (en la medida en que hay una cronología de hechos que puede ser verificada), se nos habla de la visita familiar que el personaje le hace a Bolaño en Blanes, y de la intervención en foros y presentaciones de libros. De este escritor chileno fallecido precisamente cuando ha logrado instalarse en la casa local y en la global, se nos dice: "Lo suyo era más bien un asunto de provocaciones

$12 \quad$ La recepción periodística de Veneno fue escasa: "Yo hubiese esperado una conversación, pero este libro nunca fue sometido a escrutinio", confiesa el autor (en entrevista de Macarena Gallo, "Roberto Brodsky y el ambiente literario"). Ahora bien, cuando la hubo, se le criticaron las supuestas alusiones negativas hechas a protagonistas de la escena crítica y editorial chilena. Así, por ejemplo, el prestigioso crítico Ignacio Echevarría escribe: "No soy capaz de identificar a todos [los nombrados, personas de la vida real], y puede que algunos sean construcciones armadas a partir de varias personalidades. Pero ha vuelto a producirme estupor, muy en particular, el dibujo de uno de ellos, basado supuestamente en uno de mis más admirados y queridos amigos en Chile, y en el que me resulta imposible reconocer los rasgos que Brodsky le atribuye, convirtiéndolo en una especie de mefistofélico manipulador de los hilos que manejarían el reducido círculo del mundillo literario chileno" (en Ignacio Echevarría, "Veneno"). Obviamente, una lectura demasiado referencial y local posterga un radio más global de recepción y una lectura semiótica más compleja de este texto. ¿Los riesgos de la escena autobiográfica? 
imprescindibles, una búsqueda desesperada de contrincantes y aliados de la misma especia. Necesitaba una guerra para vivir y escribir como lo hacía, es decir con la muerte viva en su cuerpo, enfermo hasta las narices" (165).

Los paralelismos son evidentes: un escritor que también está volviendo con una novela bajo el brazo, premiada (la llamada novela del padre, cuyo doble en lo real es Bosque quemado, Premio Jaén), en busca de un reconocimiento que se sabe desde un principio será mezquino; un héroe que vuelve por lo suyo y nunca sabrá en qué medida lo logró -Bolaño: "el pasajero furioso que regresaba a Chile a cobrar su lugar", 142.

El regreso a casa está marcado por una itinerancia continua, que hace al personaje buscar modelos de vida y modelos de escritura (la autobiografía, la escritura ensimismada, el yo aprendiendo a decir yo). En el transcurso de su autonominación, la autoría va recolectando sujetos y formatos que le otorguen modelos para su autoimagen. Desde su guarida extranjera en Washington D.C. descubre -en esos maravillosos barcos que son las bibliotecas-el Diario de Ángel Rama, intelectual conocido por sus ensayos críticos sobre literatura y cultura. Exiliado uruguayo, sufre de un "irremediable nomadismo" (297), siendo una de sus estancias la ciudad donde está el mismo Shapiro. "Luego, Rama se pregunta qué hace en Washington, qué sentido tiene seguir viviendo en Washington" (295). Comparten el sinsentido del desarraigo, que en el caso de nuestro personaje lo lleva consigo al lugar de origen.

Siguiendo en la línea uruguaya de exilios y retornos, otra alusión para un bosquejo de sí mismo es al escritor Juan Carlos Onetti, que escribe como Diario un relato anterior suyo malogrado. La cita de Onetti es relevante, porque nos conecta a la obra total onettiana que se desarrolla en un espacio bosquejado por un personaje de su primera novela -la villa de Santa María en La vida breve-, que va siendo poblado por otros bosquejos de personajes que incluso cambian su aspecto físico y de (sobre)nombre en las siguientes novelas. La obra de este escritor uruguayo es un mundo que se va autointerviniendo, que actúa en un tiempo que se estanca, atrapando a los seres en rituales vacíos donde se constata una regresión tanática, que tiene su foco en el cuerpo de la mujer. Este rasgo de autogeneración y derivación de una obra se exhibe plenamente en la triología de Brodsky, donde las tres novelas resurgen en la conciencia creativa de un yo a modo de una cinta de Moebius, con el agregado de que este yo juega a recrear las imágenes de su propia vida. Metaficción, en cuanto la autoría (en concomitancia con los personajes creados) reinventa 
un espacio de un modo dinámico; y biografía documentada desde el trabajo escritural del yo con los archivos que va componiendo de su propia vida ${ }^{13}$.

En Veneno el personaje visita a su hermano, quien le saca en cara haber publicado una biografía familiar: "la falta de pudor incordiaba a Rubén" $(379)^{14}$. Es la novela del padre, donde el hijo sin nombre propio lo sigue en el exilio como si fuera su escudero para cuidarlo de los males que lo asedian. Sin embargo, Shapiro le confiesa a su hermano que en la vida no ocurrió así, abriendo un paréntesis de duda sobre la objetividad de ese relato. ¿Se narraron los hechos y las emociones asociadas a ellos tal como sucedieron en la vida? Shapiro (cuyo nombre no se pronuncia en el primer libro ni tampoco en el último) confiesa: "Porque yo nunca me quedé a su lado en el exilio: yo lo abandoné, sencillamente. ¿Te das cuenta? Lo dejé solo. Pero el libro parece decir todo lo contrario" (381). Ahora bien, el sentido último de ese relato no

13 Las menciones a Onetti ocurren justo en el único capítulo de Veneno redactado en primera persona, donde se ensayan borradores que continúan la historia de Bruno Marconi (personaje de El peor de los héroes, de R. Brodsky), abogado de procesos judiciales adscritos a asesinatos y desapariciones durante la dictadura chilena. De modo análogo a los procedimientos de invención del escritor uruguayo, aquí un personaje que dice yo (alter ego del autor) retoma materiales antiguos y los incluye en una nueva unidad. Así, un antiguo thriller policial (El peor de los héroes) es reengendrado desde un relato autobiográfico posterior (Veneno). Proponemos, entonces, que la escena autobiográfica se puede constituir como la matriz que reconfigura toda la obra anterior de este autor. Un detalle: en la última escena de Veneno (redactada desde la tercera persona, como casi todo el libro), el escritor Shapiro visita a Rita en su casa y luego, en su pieza (ella es la compañera de Bruno Marconi en el thriller), desenvolviéndose un incesto en múltiples niveles. Expliquemos este incesto: un personaje de un relato entra a otro (que supuestamente ya había terminado); un autor (disfrazado de personaje) en nupcias con una ninfa de su primer libro (antaño ciega y ahora vieja, reeditando a Edipo y Yocasta); en fin, el cruce incestuoso (prohibido, tabú) del escritor y su creación, del autor entreverado con sus personajes.

14 En Acto de presencia, Sylvia Molloy propone que uno de los rasgos distintivos del autobiógrafo hispanoamericano es la excesiva autocensura: "en su relato de vida introduce silencios que apuntan a lo que no puede contarse, mientras que en otros textos menos comprometedores a menudo revela lo que considera impropio de ser contado autobiográficamente" (16). Por su parte Lorena Amaro, en su artículo "Que les perdonen la vida: autobiografía y memorias en el campo literario chileno" declara la inhibición de los autógrafos chilenos para hablar directamente en primera persona: "Resulta particularmente de interés observar la posición incómoda de sus cultores, quienes deben justificar el empleo de la primera persona y la singularidad de su experiencia, en un medio en que prima la valoración del pudor" (5). Este gesto pudoroso ha sido abandonado en las autobiografías chilenas publicadas en los últimos veinte años, especialmente las escritas por los más jóvenes -estamos pensando en los relatos de Rafael Gumucio y Alberto Fuguet, y en la biografía familiar de Pilar Donoso. 
admite dobleces, aunando a los dos protagonistas de la novela: "por sobre todo primaba la necesidad de reconocimiento de una historia [la de mi padre] que no admitía indignidades" (278).

Queda claro que "Vida" y el "Relato de una Vida" no coinciden, pero sí forman un solo cuerpo compuesto desde su similitud, oposición, complementariedad, exclusión y de todas las operaciones que lo abren y clausuran. Aquí, el ejercicio autobiográfico corrige retroactivamente la vida, le superpone otro sentido, operando como un corrector de memoria o como un relato presente que trasciende ${ }^{15}$.

\section{CASA CHILENA: LAS PISADAS DEL HOGAR}

Si convenimos que esta trilogía está animada por el hilo de una misma vida registrada en distintas voces personales que la generan y sostienen, nombremos algunas conexiones entre Veneno (2012) y la última recreación, Casa chilena (2015). Teniendo en cuenta que en ambas hay un regreso al lugar natal, en Veneno el personaje que vuelve es un escritor de nombre Shapiro, en busca de una inserción y reconocimiento en el mundo cultural y artístico. Es como si el personaje del autor (el autor definido como alguien que escribe y publica) volviera a Chile de modo clandestino, bajo otro nombre (otra chapa) para constatar que está fuera de lugar ${ }^{16}$. Quien vuelve ahora, en Casa chilena, a cuarenta años del Golpe Militar, es alguien que se enuncia desde la segunda persona, como si quisiera ser un testigo (distanciado) de sí mismo. El personaje regresa a su casa de infancia, para despojarse de ella, vendiéndola al mejor postor en el mercado inmobiliario. Es una regresión controlada, que le permita deambular sin rumbo por su antiguo barrio de Ñuñoa (de Santiago de Chile), constatando la pérdida: de los objetos, de las amistades, del hogar.

15 Citemos aquí un extracto del texto fundacional de Georges Gusdorf "Condiciones y límites de la autobiografía", que consideramos pertinente en esta instancia: "se puede distinguir, en la creación literaria, una especie de verdad en sí de la vida, anterior a la obra y que vendría a reflejarse, directamente en la autobiografía, y más o menos indirectamente en la novela o el poema... . . . La autobiografía es vivida, representada, antes de ser escrita; impone una especie de marca retrospectiva al acontecimiento" (17).

16 "El autor no es una persona. Es una persona que escribe y publica. A caballo entre lo extratextual y el texto, el autor es la línea de contacto entre ambos" (Lejeune 51). 
Es el derrumbe de las ilusiones (la palabra derrumbe es recurrente en el texto), exhibido en la venta de su casa, que será demolida para dar cabida a edificios de altura: es la economía neoliberal de mercado que reconfigura un espacio urbano que deja al personaje sin memoria. Y sin embargo, solo habrá recuerdo si se constata en terreno la pérdida. En la actualidad, la casa (no vendida) es como un cuerpo fantasma (que ya murió); por ello -desde nuestra interpretación- para volverla a la vida bastará con mirarla por última vez y así, desprenderse de ella.

Si en Veneno la figura del doble aludía a la imagen del escritor (por ejemplo, el posible regreso del héroe, boicoteado por él mismo; léase, Bolaño); aquí el doble tiene varias variantes, una de las cuales está adscrita a imágenes del pasado que no han evolucionado, a la rabia y melancolía de un individuo que no quiere dar cuenta de un tiempo transcurrido. Así, nuestro personaje observa a los moradores de su casa, desde un ventanal de una casa vecina, cual voyeur. Es un matrimonio amigo -Tito e Ingrid-, que no quiere entregar la casa y más aún, no ha pagado el arriendo durante el último tiempo.

Esta pareja (Tito e Ingrid), junto a la de la casa vecina desde el cual nuestro personaje espía (Milton y Teresa, también amigos de toda una vida), son dobles de la pareja que forma el protagonista con Gloria (quien se ha quedado en Estados Unidos; pero que interviene activamente en todas las decisiones vía internet y por teléfono). Por un lado, aparece la pareja en crisis -derrumbe de la familia-, en estado regresivo y larvario, sin querer dejar un espacio que fue, pero que ya no es, y por ello proponemos que la casa está habitada por fantasmas (Tito e Ingrid, y aquí es el hombre el que más resiste). Y por el otro, desde la casa vecina donde se espía, una pareja armónica, Milton y Teresa, que al igual que el personaje, ha decidido vender, para acomodarse en un barrio vecino -Milton, una alusión al paraíso perdido. Es como si se proyectaran en la pantalla visiones de uno mismo, imágenes con las cuales convivimos y de las que no nos podemos deshacer. En realidad, el personaje vuelve para consolarse, arropar a esos seres atrapados en el pasado e incluirlos en la vida presente y darles un destino.

Siguiendo con la comparación entre estas dos novelas, hay un cambio drástico en la extensión de las oraciones: a las digresiones de Veneno, sostenidas en frases laberínticas y cavilosas; le corresponden frases breves, que a lo más se distienden con explicaciones que van entre paréntesis (y que el lector las puede saltar en la fluidez de la lectura, para llegar más pronto al punto de llegada). Se podría especular que en este tercer libro, el autor ha decidido seguir los consejos de sus personajes editores de Veneno, que le reprochan 
cierta dispersión melancólica en su prosa. En realidad, esas frases extensas señalan el vacío que el sujeto pretende llenar para así unir origen y destino ${ }^{17}$.

Las frases breves de Casa chilena sitúan al yo en una situación más comunicativa con el lector-recordemos que se usa la segunda persona-, como si el sujeto tuviera un blanco hacia el cual apuntar, aunque sea un blanco móvil. A nivel artístico, un estilo no es mejor que el otro; solo marcan dos perspectivas existenciales: el ensimismamiento (la constante cavilación) y el gesto de movimiento hacia afuera y hacia adelante. Así, a los circunloquios en torno a un origen culposo, le sucede una frase con destino-destino pobre y limitado, pero que está sustentado en un pasado que se removió. Sin embargo, no se crea que el mundo caviloso y digresivo ha desaparecido, pues esa frase con destino contiene todos los márgenes abiertos en los libros anteriores, que están allí apenas controlados por estos sintagmas breves que pretenden lograr la complicidad del lector, para una inserción nueva en el lugar de origen.

En Casa chilena, el personaje no se distrae tanto en frases laberínticas, sino que en incansables caminatas por su barrio de infancia, donde constata el arrasamiento del lugar. Ahora el personaje sufre la tensión entre lo antiguo (casas y plazoletas esfumándose) y lo nuevo (edificios y patios de cemento), moviéndose en dos tiempos: regresa en el presente. Será el cuerpo (el esfuerzo físico del desplazamiento) y la mente (el ejercicio de superposición de imágenes que realiza de lo actual y de lo lejano), lo que lo haga rendirse a la escritura más acotada. Es también la edad, el cierre de una crisis o al menos el reconocimiento del movimiento perpetuo en que se está: ir y venir, sin descanso, constatando una pérdida que cruza la familia y los ideales políticos y que constituye el motor de la escritura.

Si Veneno enfatiza las condiciones autodestructivas de las relaciones humanas (narcisismo, odiosidad, antipatía), Casa chilena es más bien lúdica, gozando con la amistad de los personajes y sus juegos cómicos, como si se viviera en otra esfera. Estamos pensando en las escenas donde platican el personaje y

$17 \quad$ Aludimos aquí a la relevancia del discurso en la constitución del sujeto en el ámbito del psicoanálisis. Citemos a Jacques Lacan: "El inconsciente es aquella parte del discurso concreto en cuanto transindividual que falta a la disposición del sujeto para restablecer la continuidad de su discurso consciente" (79). Elucubramos que estas frases de amplísimo radio, que dispersan sus referentes, que juegan a desenfocarse, estarían -más que ningún otro tipo de frases- en la huella del inconsciente, remarcando la extrema dificultad (o imposibilidad) de los sujetos para autodescubrirse. Nos hemos permitido este alcance, por ser nuestro personaje Alberto Shapiro un lector de Lacan. 
un gran amigo suyo, que aparece bajo el nombre de C. Cual dos comediantes, conversan como si estuvieran actuando para entretener a la audiencia. $\mathrm{C}$ es visitado en un clínica por nuestro personaje (aquí la programación de lectura del texto nos sugiere que lo nombremos con la inicial B de Brodsky). C se somete a una cirugía de aorta (justo en la misma clínica donde B nació) y se lo toma con humor. Figuras opuestas y complementarias, cuando están juntos actúan sus vidas en un libreto ingenioso, donde se habla de modo paródico de las ilusiones perdidas (corazón, comunismo, amor). Hermanados en la vida y en la literatura (los dos son creadores y comparten un pasado teatral en común), B y C logran suplir el eslabón que los precede (siguiendo con el juego de las letras: la letra A, la primera), consolándose con risas de payaso de la dificultad de retener las raíces ${ }^{18}$.

Casa chilena constata, de un modo paródico, el surgimiento de un nuevo modo de vida adscrito a la voracidad mercantil. Ante lo inevitable (la venta de la casa, que derrumba el signo de una identidad fundada en valores cualitativos), solo queda carnavalizar esta venta, transformándola en el antiguo juego de Metrópolis, donde cada participante compraba y vendía propiedades, según la suerte del golpe de dados. Así, el personaje y sus amigos Milton y Teresa, ya habiendo renunciado a sus casas, se juntan para jugar Metrópolis, haciendo un chiste de una posible nueva identidad ciudadana adscrita al capital. Por otro lado, en este juego queda claro que sus casas han desaparecido materialmente; pero no sus recuerdos, los cuales -a lo más- han quedado hipotecados. Paradójicamente, solo desprendiéndose de la casa, este personaje tiene la oportunidad de recuperar en fragmentos una infancia allí abandonada y congelada (y justo desde un juego de mesa de antaño, prácticamente desaparecido).

Tal como en Veneno, este libro prohija a los demás, volviendo a otras escenas y situaciones, para ampliarlas o desdibujarlas. Las circunstancias de la partida del padre a Buenos Aires y su estadía allí, poco tiempo después del Golpe Militar de 1973 (relatadas en el primer libro Bosque quemado), son revividas ahora ante una cámara en la grabación de un testimonio del

18 Insertamos aquí el dato - no tan visible en la actualidad- de que Roberto Brodsky ha sido actor dramático, habiendo fundado en Chile durante los años 80, junto a Gregory Cohen, la Compañía Teniente Bello. Quizás Brodsky y Cohen puedan aprovechar los ingeniosos diálogos de Casa chilena (que ya vienen dispuestos en escenografías ad hoc), para montar una pieza teatral de tono burlesco, a la usanza de las que solían ambos crear y representar en aquellos tiempos. 
personaje en la misma Villa Grimaldi (lugar de detención y tortura de presos políticos chilenos), donde aparece una imagen olvidada tanto en la mente del autor como en el primer libro: una foto tamaño carnet del padre mandada desde el país vecino, que desata la partida del hijo para acompañarlo: "él estaba irreconocible, muy demacrado y ojeroso, como despojado" (57). Los tres libros se constituyen, entonces, como cuadernos de ejercicio de memoria, que trabajan con el mismo material desde tiempos y lugares de enunciación diversos. Libro trillizo que recrea una matriz que se sustenta justamente de los remiendos que el sujeto ejercita.

Una de las características de los personajes de esta trilogía es inquirir sobre sus situaciones vitales desde acertijos que aluden a un impasse que los mantiene al margen de sí mismos. Así, en Casa chilena, se formula la siguiente pregunta: “CCómo se hace, en el fondo, para derribar una puerta abierta?" (187, cursiva en el texto). Y ante la posibilidad de iniciar o abortar un nuevo romance, el personaje reflexiona desde una frase conceptista, suspendida en los extremos: "Quiere terminar algo que nunca empezó" (185). ¿Se está dentro o fuera? ¿Calzan las personas gramaticales con un nombre propio? ¿A dónde se regresa cuando se está en Chile? Más allá de estas incertidumbres, planteamos que el deseo de completitud es pleno: ser uno solo con lo perdido (la familia, el país, las utopías).

Si los personajes se instalan en el lugar del vacío que genera la no resolución de opuestos (ir o regresar, casa recuperada o casa perdida, yo y no-yo), el autor se posiciona en medio de las vías paralelas de la vida y la literatura. Desde Casa chilena, leemos la siguiente declaración de principios: "entre el arte y la vida, hay que elegir por ambas aunque el interés no quiera mezclarlas. ¿Será por eso que hoy dominan (y te aburren) las estéticas limpias?" (62-63, cursiva en el texto). Al respecto, indiquemos de paso que el autor reflexiona constantemente sobre una poética de la vida, anotando fichas sobre el pensamiento de otros artistas sobre esta relación. Así, también en Casa chilena, en una biografía sobre Juan Carlos Onetti pesquisa la siguiente cita: "El libro cita a Proust cuando alecciona a los lectores, diciendo que una obra es producto 'de un yo diferente al que manifestamos en nuestras costumbres"” (61). Y colgado de esta cita, declarará ensayísticamente: "Si la literatura se justifica, es porque trabaja sobre la vida propia y de los suyos, los arranca de su inercia y crea nuevas posibilidades para ellos y los lectores, del mismo modo que el actor en escena lo hace sobre los órganos y músculos de su cuerpo: en la oscuridad y el vértigo, a punto de perder pie y caer a cada instante" (62-63). 
En esta poética no hay división entre cuerpo y alma, entre contracción muscular y gesto, entre aparato de fonación y voz con sentido; en fin, entre pensamiento y escritura. Existiría un sostén -la vida como columna vertebral-sobre el cual trabaja la forma. En estos bosquejos de una poética, hay convergencias y divergencias con otras teorías que tanto privilegian el relato autobiográfico como estrictamente confesional (adscribiéndose a un pacto referencial de veracidad) o como autoficción (donde la referencia es solo el nombre propio, no habiendo un pacto obligado con los hechos de la vida) ${ }^{19}$.

\section{COLOFÓN: LAS TRAMAS DEL YO}

Culminando este recorrido de orden circular, volveremos la mirada sobre los títulos de las obras que componen esta trilogía. En el origen, Bosque quemado, la desaparición de un sentimiento comunitario, una catástrofe que afecta a toda la humanidad. Los discursos alusivos son aquí el holocausto, las dictaduras recientes latinoamericanas y acaso, las crisis del pensamiento utópico que fundaba las nociones de revolución, amor romántico y felicidad familiar.

Esta imagen catastrófica se modifica en Casa chilena, al incluirse un gesto paródico en la constatación, ahora marcadamente consciente, del derrumbe de un mundo afectivo y de valores a los cuales el personaje está adscrito.

19 Hay una innumerable bibliografía crítica sobre el relato autobiográfico, que actualiza el debate epistemológico sobre la representación o producción de lo real (por ejemplo, de modo más concreto, entre veracidad y verosimilitud, entre realidad y ficción). Junto a la noción de pacto autobiográfico de Lejeune, que implica la identidad de autor, narrador y personaje, y que está sustentado en un relato veraz (que se opone a un pacto novelesco, de carácter ficticio y no avalado por el principio de identidad anterior), aparece la noción de autoficción, que en la versión de Manuel Alberca plantea un pacto ambiguo, por el cual el autor coincide en su nombre con el narrador y el personaje, pero sus enunciados son una mezcla de la factualidad de la autobiografía y de la ficción de la novela. En palabras de Alberca: "El autor de autoficciones no se conforma sólo con contar la vida que ha vivido, sino en imaginar una de las muchas vidas posibles que le podría haber tocado en suerte vivir" (33). Para una revisión actualizada de la autoficción, consúltese el conjunto de trabajos compilados por Ana Casas en El yo fabulado. La tríada de Brodsky plantea desafíos tanto para la propuesta de Lejeune -indicar que son novelas autobiográficas traiciona en parte la noción de identidad que sustenta su obra narrativa- como la de Alberca - señalar que son autoficciones bloquea la posibilidad del recuerdo como cavilación perpetua. Ya habrá otra oportunidad para despejar la identidad y el tiempo desde el discurso psicoanalítico, muy en consonancia con el espíritu de sus personajes y sus dobles. 
Hay escenas cómicas en que el personaje aparece poniéndose en ridículo o sintiéndose víctima de las circunstancias, que bien pueden interpretarse como un signo de buena salud de cierto tradicional humor judío que modifica la escena de la vida, enmarcándola en el absurdo cotidiano.

Un marco existencial posible para establecer una relación entre las partes en esta trilogía es la mención de las nociones de duelo y de melancolía, propuestas por Sigmund Freud ${ }^{20}$. Así, Bosque quemado estaría habitado por un sujeto melancólico que se pega a su padre, siendo Moisés el significante de lo que se perdió y nunca más se volverá a recuperar -la patria, una ilusión, la misma armonía familiar. En realidad, el mismo padre es un cadáver viviente; por lo cual su adherencia a él le impide al hijo cualquier proyección tanto sentimental como ideológica. La migrancia del hijo por distintos puntos del mapa siguiéndole las huellas al padre (la circulación en redondo) es, en este ámbito, el signo de una pérdida de referentes -no olvidemos esta declaración: "mi padre era mi país, mi patria portátil. Yo sería del lugar donde estuviese él” (70).

Por su parte, en Casa chilena el hijo vende la casa familiar de la infancia justamente para salir de ese espacio encapsulado y así desprenderse definitivamente de una casa fantasma. Solo separándose de ella, podrá situar ese recuerdo en el flujo de la conciencia, haciéndola circular con otras imágenes. Es el trabajo del duelo, la posibilidad afectiva de abandonar lo ya ido: matar al muerto, justamente para habitar la vida.

El título Veneno es una condensación de ideas y pulsiones contrapuestas. Por una parte, Shapiro se siente llamado por los suyos: Ven, parecen decir (pues recibe una invitación aparentemente prestigiosa). Es el regreso del héroe. Y al mismo tiempo, si leemos de atrás hacia adelante el título, aparece bajo cuerda: No Vengas. En esta obra, el sujeto experimenta una ambivalencia en cuanto a permanecer (o no) en el lugar de origen. ¿Cómo concebir ese origen? ¿Y qué significa el lugar alterno? Considero que la delimitación del tránsito del personaje a dos puntos en el eje vertical Norte/Sur (que alcanza también a Casa chilena) constituye ya un distanciamiento del momento

20 En términos freudianos, la melancolía es la fijación del sujeto a un objeto perdido -el ser amado, la libertad, la patria- y la búsqueda infructuosa de ese objeto en el presente. Por su parte, el duelo consiste en el trabajo de desprendimiento del sujeto de esa fijación: el yo (en un gesto narcisista que lo liga a la vida) recupera su amor propio, rompiendo su lazo con el objeto desaparecido. Cf. "Duelo y melancolía" de S. Freud y la entrada correspondiente a Trabajo de Duelo en el Diccionario de psicoanálisis de J. Laplanche y J.-B. Pontalis. 
melancólico (que lo mantiene disperso en el mapa en el primer libro): desde un nuevo lugar se toma distancia del lugar inicial. Y sin embargo, la dificultad del desprendimiento no desaparece, con el riesgo que el lugar alterno sea un doble del original.

Por cierto, Veneno, en su acepción primera, es una sustancia nociva para la salud, que puede causar la muerte y también indica, a todas luces, un mal sentimiento. ¿Dónde situar el veneno? Recordemos que Bosque quemado remite también a la expresión burn out, asociación puesta en boca del mismo personaje: quemarse junto al enfermo, contaminarse con su estado de ánimo; en fin, morir con él. Casa chilena es la obra donde el personaje pretende desprenderse de un sentimiento de autodestrucción que surge del mismo espacio valórico y cultural de la nación. La trilogía será entonces el viaje mítico de alguien que debe dar digna sepultura al padre, reivindicando a ambos desde su condición de escritor, en un relato imposible: estar afuera y adentro de lo perdido y lo ganado.

Si escribir es una forma de recordar, el título Veneno alude a la relación entre escritura y memoria. El intertexto es aquí la discusión sobre el mito de los orígenes desde el comentario de Jacques Derridá: la escritura es un pharmakon para la memoria, es decir, un remedio; pero también su contrario (un veneno), puesto que la sustituye, no haciendo un calce perfecto con ella ${ }^{21}$. Veneno se transforma entonces en la puesta en escena del drama humano de nunca poder lograr la unidad (consigo mismo, con el otro, en el transcurso del tiempo).

El juego de identidades se presenta en el constante desplazamiento de la persona gramatical cuando se pasa de una obra a otra. Primero, aparece alguien que dice $y o$, pero ese espacio puede ser ocupado por cualquier nombre propio, pues nunca se nombra de modo directo (aunque sí es aludido constantemente). En realidad quien habla es el hijo de Moisés Brodsky: es la trama del hijo. Luego, en la segunda obra, el personaje tiene nombre (Alberto Shapiro) y está presentado desde la tercera persona. Y sin embargo, el relato permite que el lector lo lea como si estuviera escrito en primera persona, logrando así que

21 Retomamos aquí la lectura de Carlos Peña sobre Veneno a partir del texto La Farmacia de Platón de Jacques Derridá. De modo ensayístico, Peña concluye: "La memoria y la literatura son así, un bosque quemado (para usar el título de otra de sus novelas): hay en ellas rastros de lo que ocurrió y de lo que nos angustia o lo que nos desola, y zonas reverdecidas, pero el conjunto fidedigno que nos constituye fue incinerado por el tiempo y lo único que entonces podemos hacer, es usar la literatura para intentar remedarlo" (124). 
el nombre de Shapiro se traslape con el innominado del primer relato. Y en la última obra, alguien nos habla desde un tú; es decir, a nivel lingüístico, desde un no-yo, en un esfuerzo máximo de salida de sí mismo.

Así, la identidad del personaje surge desde la visión caleidoscópica de la categoría de persona gramatical, donde el conjunto se sostiene en la noción del yo como un juego de sustituciones y desplazamientos, llenados por una identidad en tránsito: el hijo (que dice yo), alguien llamado Shapiro - un yo enmascarado, pues podemos jugar a insertar el pronombre cada vez que aparece y así leer "[Yo], Shapiro"; y en la medida en que excepcionalmente también habla en primera persona, leer "Yo, autor de un thriller"-y, por último, alguien concebido como un eco del yo (un no-yo, su revés, un distanciamiento de sí mismo, sin que ello conlleve la alteridad; por el contrario, siendo un ensimismamiento) ${ }^{22}$.

Culminemos esta reflexión insistiendo en la singularidad de esta composición triádica, la cual tendría la potencialidad de abarcar las escrituras futuras del autor y recomponer las obras que la preceden. ¿Será que el primer libro, Bosque quemado, engendre a Veneno y a Casa chilena, cumpliendo éstos solo funciones específicas? ¿Se agotará todo así en una causa primera, según el modelo del árbol ya contenido en la bellota? Lo cierto es que cada libro tiene la virtud de volver a engendrar a su anterior y anticipar el orden siguiente. Estamos, entonces, en el modelo de un sistema que se va autogenerando, trabajando y recomponiendo un mismo material.

La composición de estos libros (de mutua dependencia y autoengendramiento) privilegia homologías de carácter estructural, desatando un juego de simetrías, paralelismos y contrastes tanto en la anécdota como en sus circuitos narrativos. Así, por ejemplo, existe una programación de lectura que invita al lector a establecer vínculos entre el hijo de Moisés (que no tiene nombre propio) y el hijo de Shapiro llamado familiarmente Fer (nombre abreviado, signo de carencia), quien también aparece viajando para conectar a sus progenitores. Situaciones que se engendran desde la repetición de acciones (los viajes familiares en busca de una casa que nunca está en su lugar), de motivos (las

22 Estos comentarios sobre la categoría gramatical de persona tienen en consideración los planteamientos de Ėmile Benveniste sobre la naturaleza de los pronombres -“yo es el individuo que enuncia la presente instancia del discurso que contiene la instancia lingüística $y o$ ", 173 -y la subjetividad de la lengua: "Es en y por el lenguaje como el hombre se constituye como sujeto; porque el solo lenguaje funda en realidad, en $s u$ realidad que es la del ser, el concepto de ego" (180). 
acciones de arte como pantalla de autorrevelación: Orimoto y los afectos perdidos, Rotko y los límites de la mimesis), de afectos (duelo y melancolía, rebelión y culpa) y procedimientos -el doble y el juego con la categoría de persona gramatical que articulan al sujeto desde sus obsesiones y sus perspectivas enunciativas.

En resumen, una tríada en que cada uno de los libros está interviniendo en los demás y procrea su futuro. ¿Cómo proseguirá este relato, cuál será su siguiente historia? Desde Veneno -el texto más seminal de los tres-, conjeturamos que puede girar en torno la figura de Enrique Lihn durante los años 80 (tiempos de exilio interior), padre simbólico de una casa chilena semiabandonada ${ }^{23}$.

Un alcance final sobre literatura y vida. Siguiendo las disquisiciones autoriales, se puede especular que la literatura abre nuevas posibilidades a nuestra vida, superponiéndole una realidad síquica (y aquí, otorgamos una impronta freudiana a nuestro discurso). Pero eso es posible en la medida en que la literatura tenga como objeto la vida de un individuo, confundiéndose con ella. El escenario autobiográfico se revela entonces como un lugar de cruce que posibilita una reflexión trascendente sobre el paraíso perdido, pues solo allí los recuerdos se hacen vivos. Un escenario en penumbras donde se atisban las sombras del tiempo absoluto de la reminiscencia.

\section{BIBLIOGRAFÍA}

Alberca, Manuel. El pacto ambiguo. De la novela autobiográfica a la autoficción. Madrid: Biblioteca Nueva, 2007.

Amaro, Lorena. "Que les perdonen la vida: autobiografía y memorias en el campo literario chileno". Revista Chilena de Literatura 78 (2011): 5-28.

Vida y escritura. Teoría y práctica de la autobiografía. Santiago: Pontificia Universidad Católica de Chile, 2009.

Benveniste, Èmile. Problemas de lingüistica general. México: Siglo XXI, 1971.

23 La sospecha está fundada en un colofón del libro, donde Brodsky cuenta que un comentario sobre su obra Bosque quemado aparece ilustrado en un periódico español con la foto de Enrique Lihn (y no con la suya). Lihn, un modelo de artista a seguir (como Onetti, como Rama), alguien que intervine en la vida cotidiana de la dictadura con su personaje Pompier, que es necesario devolverlo a la memoria, muy especialmente en la actualidad, cuando se lo reifica desde la lógica del mercado como un ídolo pop. 
Brodsky, Roberto. Casa chilena. Santiago: Random House, 2015.

Veneno. Santiago: Mondadori, 2012.

Bosque quemado. Mondadori, 2007.

El peor de los héroes. Santiago: Alfaguara, 1999.

Cárdenas, M. Teresa. "Roberto Brodsky y el imposible regreso". El Mercurio [Santiago, Chile] 27 Sept. 2015: E11.

Casa, Ana (ed.). El yo fabulado. Nuevas aproximaciones críticas a la autoficción. Madrid/ Frankfurt: Iberoamericana Vervuert, 2014

Echevarría, Ignacio. "Veneno". El Mercurio [Santiago, Chile] 24 Feb. 2013, s.p. WEB 1 Feb 2016. Recuperado de http://www.elmercurio.com/blogs/2013/02/24/9534/Veneno.aspx

Freud, Sigmund. "Duelo y melancolía". Obras completas. T. II. Madrid: Biblioteca Nueva, 1973. 2091-2100

Gallo, Macarena. "Roberto Brodsky y el ambiente literario chileno". The Clinic [Santiago, Chile] 28 Oct. 2015, s.p. Web 1 Feb. 2016. Recuperado de: http://www.theclinic.cl/2015/10/28/ roberto-brodsky-y-el-ambiente-literario-chileno-aca-te-sacan-la-chucha-y-te-la-van-aseguir-sacando-siempre/

Gusdorf, Gustav. "Condiciones y límites de la autobiografía". Loureiro, Ángel (ed.). La autobiografia y sus problemas teóricos. Barcelona: Anthropos, 1991. 9-18.

Huyssen, Andreas. En busca del futuro perdido. Cultura y memoria en tiempos de la globalización. Buenos Aires: Fondo de Cultura Económica de Argentina, 2001.

Lacan, Jacques. Escritos I. México: Siglo XXI, 1972.

Laplanche, Jean y J.B. Pontalis. Diccionario de psicoanálisis. Madrid: Labor, 1971.

Lejeune, Philippe. "El pacto autobiográfico". Loureiro, Ángel (ed.). La autobiografía y sus problemas teóricos. Barcelona: Anthropos, 1991. 47-61.

Lyotard, J.-F. La condición postmoderna. Madrid: Cátedra, 1989.

Loureiro, Ángel (compil.). La autobiografía y sus problemas teóricos. Barcelona: Anthropos, 1991.

Mizón, Luis. "Pensar Chile desde fuera". Montecino, Sonia (compil). Revisitando Chile. Identidades, mitos e historia. Santiago: Cuadernos del Bicentenario, 2003. 283-288.

Molloy, Sylvia. Acto de presencia. La escritura autobiográfica en Hispanoamérica. México: Colegio de Méxio-Fondo de Cultura Económica, 1996

Montecino, Sonia. Revisitando Chile. Identidades, mitos e historia. Santiago: Cuadernos del Bicentenario, 2003.

Peña, Carlos. "Veneno”. Hispamérica 127 (2014): 122-124.

Pizarro, Ana. "Mitos y construcción del imaginario nacional cotidiano". Montecino, Sonia (compil). Revisitando Chile. Identidades, mitos e historia. Santiago: Cuadernos del Bicentenario, 2003. 85-91.

Rebolledo, Loreto. "De la isla al archipiélago. La experiencia identitaria de los chilenos retornados". Montecino, Sonia (compil). Revisitando Chile. Identidades, mitos e historia. Santiago: Cuadernos del Bicentenario, 2003. 289-294. 
Scherman, Jorge. "En nombre de Moisés (Bosque quemado de Roberto Brodsky)". Taller de letras 51 (2012): 179-201.

Trigo, Abril. "Migrancia: memoria: modernidá". Moraña, Mabel (ed.). Nuevas perspectivas desde/sobre América Latina: el desafio de los estudios culturales. Santiago: Cuarto Propio, Instituto Internacional de Literatura iberoamericana, 2000. 273-291. 